\title{
Vectors expressing chimeric Japanese encephalitis dengue 2 viruses
}

\author{
Y. WEI ${ }^{1}$, S. WANG ${ }^{2}, \mathrm{X}$. WANG ${ }^{2 *}$ \\ ${ }^{1}$ Department of Environmental Health, School of Public Health, Guiyang medical University, Guiyang, P. R. China; ${ }^{2}$ National Institute \\ for Viral Disease Control and Prevention, Chinese Center for Disease Control and Prevention, Beijing, P. R. China \\ Received February 24, 2014; accepted November 12, 2014

\begin{abstract}
Summary. - Vectors based on self-replicating RNAs (replicons) of flaviviruses are becoming powerful tool for expression of heterologous genes in mammalian cells and development of novel antiviral and anticancer vaccines. We constructed two vectors expressing chimeric viruses consisting of attenuated SA14-14-2 strain of Japanese encephalitis virus (JEV) in which the PrM/M-E genes were replaced fully or partially with those of dengue 2 virus (DENV-2). These vectors, named pJED2 and pJED2-1770 were transfected to BHK-21 cells and produced chimeric viruses JED2V and JED2-1770V, respectively. The chimeric viruses could be passaged in C6/36 but not BHK-21 cells. The chimeric viruses produced in C6/36 cells CPE 4-5 days after infection and RT-PCR, sequencing, immunofluorescence assay (IFA) and Western blot analysis confirmed the chimeric nature of produced viruses. The immunogenicity of chimeric viruses in mice was proved by detecting DENV-2 E protein-specific serum IgG antibodies with neutralization titer of 10. Successful preparation of infectious clones of chimeric JEV-DENV-2 viruses showed that JEV-based expression vectors are fully functional.
\end{abstract}

Keywords: Japanese encephalitis virus; dengue 2 virus; chimeric virus

\section{Introduction}

Flaviviruses belong to the family Flaviviridae, which are single stranded positive sense RNA viruses. The genomic RNA is $11 \mathrm{~kb}$ long containing single open reading frame (ORF). The organizational pattern of the genome is $5^{\prime}$-NCRC-PrM/M-E-NS1-S2B-NS3-NS4A -NS4 B-NS5- NCR-3. The $\mathrm{E}$ protein encoded by $\mathrm{E}$ gene is a viral envelope glycoprotein, which is an important viral antigen binding to cell surface receptor, mediating membrane fusion, and inducing neutralizing antibody. The PrM/M protein encoded by the PrM gene is considered as another important antigen that induces neutralizing antibody. Non-structural gene and non-coding regions (NCR) are related to virus replication and protein translation.

*Corresponding author. E-mail: wangxiaofang90@163.com; phone: +86-10-58900673 Yan Wei and Shiwen Wang contributed equally. Abbreviations: $\mathrm{CPE}=$ cytopathic effect; $\mathrm{DENV}-2$ = dengue virus 2; IFA = immunofluorescence assay; JEV = Japanese encephalitis virus
Vectors based on self-replicating RNAs (replicons) of flaviviruses are becoming powerful tools for gene expression in mammalian cells and for the development of novel antiviral and anticancer vaccines. Kunjing, Dengue, YF-17D viruses have already been used for replicon vector construction to express foreign proteins (Khromykh, Varnavski et al., 1998; Varnavski and Khromykh, 1999; McAllister et al., 2000; Varnavski et al., 2000; Khromykh et al., 2001; Pang et al. 2001; Anraku et al., 2002; Harvey et al., 2003, 2004; Ward et al., 2003; Herd et al., 2004). There are many advantages for replicon vector applications. Firstly, a relatively small genome size and simple rapid generation of recombinants; secondly, cytoplasmic RNA amplification eliminates nuclear involvement and leads to extremely high levels of gene expression (Khromykh, 2000).

Japanese encephalitis virus (JEV) belongs to the genus Flavivirus of the family Flavividae. JEV SA14-14-2 strain, used as an attenuated live vaccine developed in China, is a sTable attenuated virus strain derived from virulent strain SA14 passaged on a monolayer of primary hamster kidney cells. More than 200 million people in China were vaccinated 
by JEV SA14-14-2 strain vaccine, demonstrating its safety and efficacy.

In this study, a full-length prM/E gene of DENV-2 (1983 bp) and a fragment (1770 bp) of this gene lacking 3'-terminal $213 \mathrm{bp}$ were inserted into the MCS of an expression vector harboring the JEV replicon. In vitro RNA transcripts from these recombinant vectors were used for expression of corresponding chimeric JED2V and JED2-1770V viruses in BHK-21 and C6/36 cells. The genome composition of chimeric viruses was confirmed by RT-PCR, IFA and Western blot analysis. The chimeric viruses could be passaged in C6/36 but not in BHK-21 cells, produced CPE and were immunogenic in mice.

\section{Material and Methods}

Virus. Dengue virus 2 New Guinea C strain (DENV-2 NGC strain) was introduced by Institute Pasteur (France) in 1978 and provided by Chinese National Pharmaceutical \& Biological Products Control Institute. JEV SA14-14-2 stain is from Chengdu Biological Product Institute. These strains were passaged no more than 3 times in our laboratory.

Cells and animals. BHK-21 cells and C6/36 cells were from ATCC, stored in our lab. Special pathogen free (SPF) Balb/C mice (6-8-week-old, female) were obtained from Institute of Laboratory Animal Sciences, CAMS\&PUMC.

Vector construction. The full-length prM/E gene (DENV-2$\mathrm{prM} / \mathrm{E}, 1983 \mathrm{bp}$ ) and $213 \mathrm{bp}$ deletion of 3 '-terminal fragment of $\mathrm{prM} / \mathrm{E}$ gene (DENV-2-1770, 1770bp) were amplified from DENV-2 virus cDNA template by Platinum Pfx DNA polymerase (Invitrogen, USA). The primer sequences for amplification of DENV-2-prM/E are: forward primer 5'-accggtTTCCATTTAAC CACA-3' (AgeI restriction site is underlined) and reverse primer $5^{\prime}$-cccgggGGCCTGCACCATGAC-3 (XmaI restriction site is underlined). The primer sequences for amplification of DENV2-1770 are: forward primer 5'-accggt TTCCATTTAACCACA-3' (AgeI restriction site is underlined) and reverse primer $5^{\prime}$-cccggg GGATCCAAAATCCCAAGCTG-3' (XmaI restriction site is underlined). The PCR amplification conditions were: denaturation at $94^{\circ} \mathrm{C}$ for $30 \mathrm{sec}$ and $25 \mathrm{cycles}$ of $94^{\circ} \mathrm{C} 15 \mathrm{sec}, 52^{\circ} \mathrm{C} 30 \mathrm{sec}$, $68^{\circ} \mathrm{C} 2 \mathrm{~min}$, with a final extension at $68^{\circ} \mathrm{C}$ for $10 \mathrm{~min}$. After PCR amplification of DNA fragment, $1 \%$ agarose gel electrophoresis was undertaken to analyze the PCR products. TA clones were designated as DENV-2-prM/E-TA and DENV-2-1770-TA and verified by restriction analyses and sequencing. pFull $\Delta \mathrm{prM} / \mathrm{E}$ and $\mathrm{pPartial} \Delta \mathrm{prM} / \mathrm{E}$ vectors were constructed using Age I and XmaI restriction enzyme digestion. Competent Escherichia coli XL1-Blue cells were transformed with the ligation products. The recombinant plasmids were verified by restriction enzyme digestion and designated as $\mathrm{PJED}_{2}$ and $\mathrm{pJED}_{2}-1770$.

$R N A$ in vitro transcription. Plasmids $\mathrm{PJED}_{2}$ and $\mathrm{pJED}_{2}-1770$ were linearized by SalI digestion and purified. In vitro transcription, RNA was prepared by RIBOMAX large scale RNA production system (Promega). Transcription was done in an $100 \mu$ reaction mixture containing $5 \times$ transcript buffer, $25 \mathrm{mmol} / \mathrm{l} \mathrm{rATP}$, rCTP, rUTP each, and $8.33 \mathrm{mmol} / \mathrm{l} \mathrm{rGTP}, 40 \mathrm{mmol} / \mathrm{l}$ of $\mathrm{m} 7 \mathrm{G}$ cap, $10 \mathrm{U}$ of T7 RNA polymerase (Promega), and $15-25 \mathrm{ng} / \mu \mathrm{l}$ of linearized plasmid. After $4 \mathrm{hr}$ incubation at $37^{\circ} \mathrm{C}, 2 \mu \mathrm{l}$ of DNase were added to the mixture and the incubation continued for an additional $20 \mathrm{mins}$ at $37^{\circ} \mathrm{C}$. The in vitro transcript was purified by RNeasy mini kit (Qiagen) and stored at $-70^{\circ} \mathrm{C}$

Preparation and passaging of chimeric viruses. BHK-21 confluent monolayer in a T25 flask was harvested by $10 \%$ trypsin, resuspended in DMEM with $10 \% \mathrm{FBS}$ and centrifuged at $400 \mathrm{x}$ g for $5 \mathrm{~min}$. The cells were washed twice with cold PBS, resuspended into $400 \mu$ of PBS, mixed with $10 \mu \mathrm{g}$ of in vitro RNA transcript and then transfected by electroporation using a Biorad Gene Pulser at settings of $850 \mathrm{~V}, 25 \mu \mathrm{F}$ capacitance, $\infty$ resistance and double pulse. The electroporated cells were immediately, after 5 min incubation on ice, transferred to six-well plates with $2.5 \mathrm{ml}$ of DMEM with $10 \%$ FBS and incubated at $37^{\circ} \mathrm{C}$. After the cells attached, culture medium was replaced with fresh medium and the incubation continued. The mock electroporated BHK-21 cells were used as negative control. The morphology of the electroporated cells was observed each day. When the transfected cells showed CPE, the BHK-21 cells with culture medium were thawed and frozen 3 times and centrifuged at 4,000 x rpm for $10 \mathrm{~min}$. BHK-21 and C6/36 cells in T25 flasks were infected by $0.5 \mathrm{ml}$ of supernatant and incubated at $37^{\circ} \mathrm{C}$ and $28^{\circ} \mathrm{C}$ for $1 \mathrm{hr}$, respectively. The infected cells were cultured in medium containing $2 \%$ FBS. The morphology of the infected cells was observed each day. The obtained chimeric virus strains were designated as JED2V and JED2-1770V.

$R T-P C R$. Total RNA from cells infected with JED2V and JED21770 V showing CPE was isolated and reverse transcribed to CDNA. PCR was carried out with the cDNA template and with primers: 5'-CGAGAACTTGGAACACTCATTGACG-3' (forward) and 5'-GCGCTTTGTGGACGATCTTCGCTAG-3' (reverse). The PCR products were verified by sequencing. RNA from non-transfected cells was used as negative control.

Immunofluorescence assay (IFA). After washing twice with PBS, JED2V and JED2-1770V inoculated cells showing CPE were resuspended in PBS. Antigen slides were prepared and fixed with cold acetone for $15 \mathrm{~min}$. Viral antigen levels were detected by recombinant DENV-2 E III protein rabbit antiserum (1:200) and Japanese encephalitis virus NS1 protein rabbit monoclonal antibody (1:400). FITC conjugated goat anti-rabbit serum was used as secondary antibody (1:100). Samples were analysed in the fluorescence microscope (Nicon).

Western blot analysis (WBA). JED2V and JED2-1770V infected cells showing CPE were lysed in cell lysis buffer on ice for $30 \mathrm{~min} .40 \mu \mathrm{l}$ of cell lysates with $5 \times$ loading buffer were boiled for $3 \mathrm{~min}$ and centrifuged at $12,000 \mathrm{x} \mathrm{rpm}$ for $10 \mathrm{~min}$. The supernatants were subjected to SDS-PAGE. The proteins were transferred to a PVDF membrane by a semi-dry transfer apparatus. Viral protein levels were detected by recombinant DENV-2 E III protein rabbit antiserum (1:200) and Japanese encephalitis virus NS1 protein rabbit monoclonal antibody (1:400). 
HRP conjugated goat anti-rabbit antiserum was used as secondary antibody (1:100) and proteins were visualized by DAB staining.

Immunization of mice. The supernatant containing chimeric virus was collected from C6/36 cells at the 4 th passage and filtered through $0.45 \mu \mathrm{m}$ filter membrane. The viral titers were measured by performing tissue culture infectious dose $50 \%$ endpoint titers $\left(\mathrm{TCID}_{50}\right.$ ) and adjusted to $10^{-5}$ by RPMI-1640 culture medium containing 1\% FBS. DENV-2 and JEV virus with the same viral titers were prepared as described before. Twenty five SPF grade Balb/C mice were randomly divided into five groups (JED2V, JED2-1770V, DENV-2, JEV, negative control) and each group consisted of five mice. The animals in control group were inoculated with RPMI1640 culture medium with $1 \%$ FBS. Mice were immunized by intraperitoneal injections of $200 \mu \mathrm{l}$ of homogenized supernatant or negative control culture medium. 4 weeks later, mice sera were collected from femoral artery blood.

ELISA of DENV-2 E-specific antibodies. 96-well plates were coated with $100 \mathrm{ng}$ per well of purified prokaryote-expressed DENV-2 E III protein at $4^{\circ} \mathrm{C}$ overnight. Plates were washed 3 times with PBST, blocked with $5 \%$ non-fat dry milk at $37^{\circ} \mathrm{C}$ for $2 \mathrm{hr}$, and washed 3 times with PBST. Collected mice sera were diluted 1:100, 200, 400, 800 in 5\% non-fat dry milk respectively. Hundred $\mu$ of sera per well were added into 96-well plates and incubated for 1 hr, followed by washing 6 times with PBST. Secondary antibody solution containing HRP conjugated goat anti-mouse IgG (1:500 in $5 \%$ non-fat dry milk) was added to the wells at $100 \mu \mathrm{l}$ per well and incubated at $37^{\circ} \mathrm{C}$ for $1 \mathrm{hr}$, followed by washing 6 times with PBST. After washing, the plates were developed in the dark by addition of $50 \mu$ of substrate $A$ and $B$ solution per well for 10 min. Fifty microliters per well of $2 \mathrm{~N} \mathrm{H}_{2} \mathrm{SO}_{4}$ were added to stop the reaction. The plates were read at absorbance $\mathrm{A}_{450}$ in an ELISA reader (Biorad).

Neutralization titration. BHK-21 cells were seeded into 96-well plates and cultivated until confluent monolayer was formed. All serum samples were heat-inactivated at $56^{\circ} \mathrm{C}$ for $30 \mathrm{~min}$ and filtered with $0.45 \mu \mathrm{m}$ filter membrane. Two-fold serially diluted sera (starting at 1:5) were incubated with an equal volume of DENV-2 virus $\left(100 \mathrm{x} \mathrm{TCID}_{50}\right)$ at $37^{\circ} \mathrm{C}$ for $1 \mathrm{hr}$. Ninety-six well plates were washed once with maintaining buffer. Two hundred $\mu \mathrm{l}$ of serum were added (in 4 parallel wells) and then incubated at $37^{\circ} \mathrm{C}$, in $5 \%$ $\mathrm{CO}_{2}$. Cytopathic effect (CPE)was observed everyday for 7 days. The neutralization titer was defined as the dilution of serum in 4 replicates that showed no CPE.

Statistic analysis. ELISA results of serum antibody levels were shown as absorbance $\mathrm{A}_{450}(\bar{x} \pm \mathrm{s})$. One-way ANOVA test was used to test the differences. Statistical analyses were performed by SPSS 16.0 software. Differences with P $\leq 0.05$ were considered significant.

Ethical aspects. This study was carried out in strict accordance with the recommendations in the Guide for the care and use of laboratory animals of Institute of Laboratory Animal Sciences, CAMS \& PUMC. The protocol was approved by the Committee on the Ethics of Animal Experiments of CAMS (Permit Number:
SCXK (Jing) 2004-0001). All surgery was performed under ether anesthesia, and all efforts were made to minimize suffering.

\section{Results}

\section{Cytopathogenicity of chimeric viruses}

Typical CPE such as cell rounding and detachment was observed in pJED2V and pJED2-1770V in vitro transcribed RNA-transfected BHK-21 cells 5-7 days after transfection. This was similar to the CPE observed in BHK-21 cells infected with DENV-2 and JEV (Fig. 1). The virus could not to be detected in BHK-21 cells in $2^{\text {nd }}$ to $5^{\text {th }}$ passage, indicating that the chimeric viruses could not be passaged in BHK-21 cells. Typical cytopathic changes such as cell swelling and aggregation were observed in C6/36 cells infected with chimeric virus JED2V and JED2-1770V 4-5 days after infection. The cytopathic changes were similar to the changes observed in DENV-2 and JEV infected C6/36 cells (Fig. 2).

\section{Identification of chimeric viruses by RT-PCR, IFA and WBA}

RNA was extracted from culture supernatant of the third generation of cells containing viral particles and reverse transcribed to cDNA. Primers were designed to amplify the region outside of chimeric virus prM/E gene and synthesized to amplify a 2,100 bp fragment from cDNA template. Nontransfected RNA served as negative control to detect DNA contamination. The sequencing results verified the chimeric gene of DENV-2 prM/E, JEV C and NS1 gene (partial JEV E gene in JED2-1770V). For chimera construction, in order to clone the exogenic gene, we introduced AgeI and XmaI restriction sites into the primer sequence.

Antigen slides were prepared by using the $4^{\text {th }}$ generation of chimeric virus infected C6/36 cells. Recombinant DENV-2 E III protein rabbit immune serum was used as primary antibody to detect DENV-2 E protein. Specific fluorescence proved the expression of DENV-2 E protein. JEV infected C6/36 cells and uninfected C6/36 cells remained negative (Fig. 3). Anti-JEV NS1 monoclonal antibody was used as primary antibody to detect NS1 protein. DENV-2 infected C6/36 cells and uninfected C6/36 cells did not interact with this monoclonal antibody and were negative (Fig. 4).

Western blot analysis was performed by using cell lysates of the chimeric virus infected C6/36 cells. Recombinant DENV-2 E III protein rabbit immune serum was used as primary antibody to detect DENV-2 E protein at molecular weight $60 \mathrm{kDa}$. Anti-JEV NS1 monoclonal antibody was used as primary antibody to detect NS1 protein at molecular weight $47 \mathrm{kDa}$ as expected (Fig. 5). 
(a)

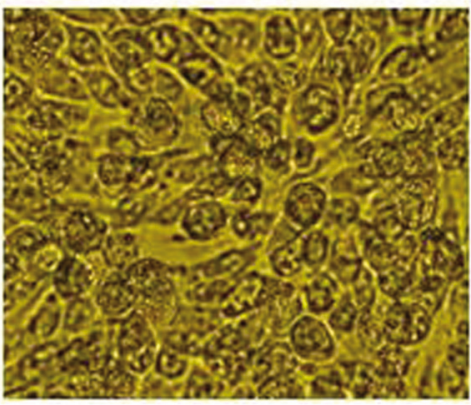

(c)

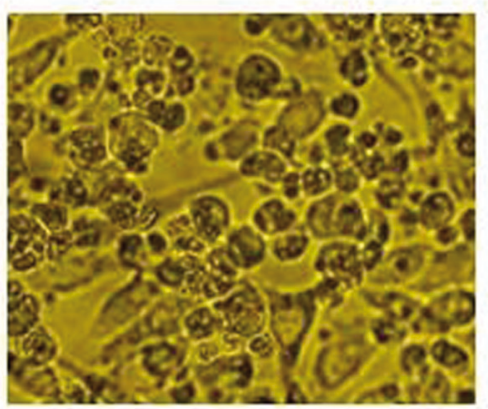

(b)

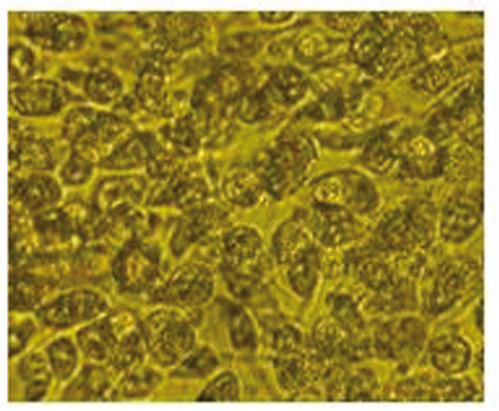

(e)

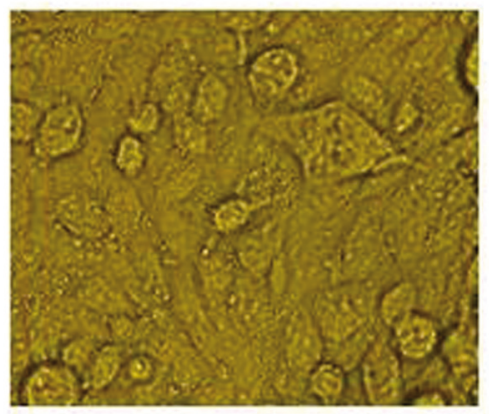

Fig. 1

CPE in BHK-21 cells transfected with vectors expressing chimeric viruses and infected with DENV-2 and JEV The legend: pJED2 (a), pJED2-1770 (b), DENV-2 (c), JEV (d), and mock (e).

(a)

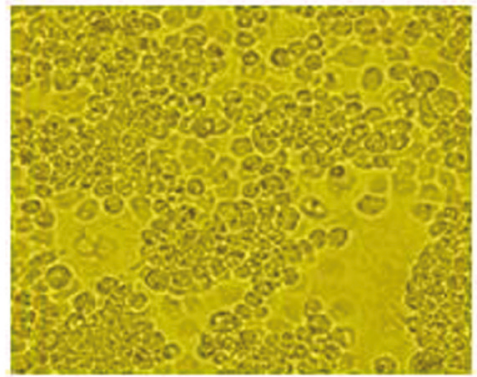

(c)

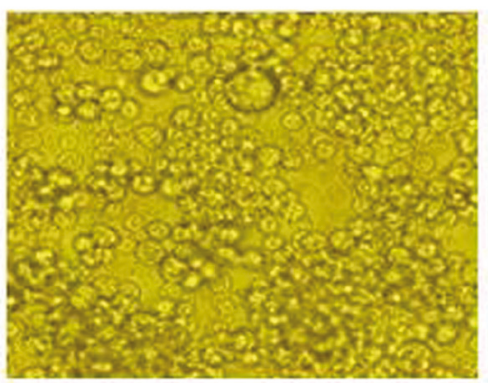

(d) (d)

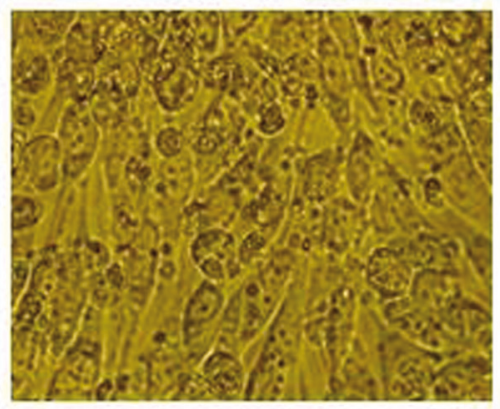

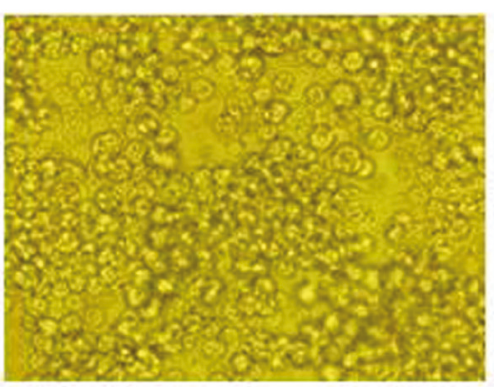

(b)

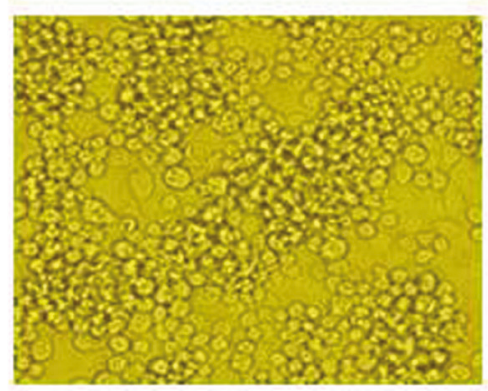

(e)

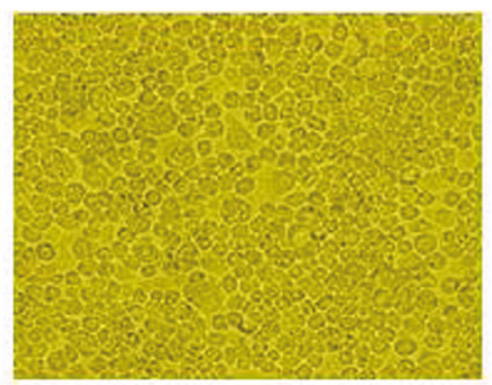

Fig. 2

$\mathrm{CPE}$ in $\mathrm{C6} / 36$ cells infected with chimeric viruses, DENV-2 and JEV

The legend: JED2V (a), JED2-1770 (b), DENV-2 (c) and JEV (d), and mock (e). 
(a)

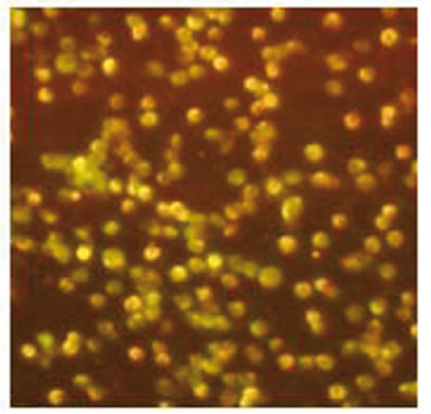

(d)

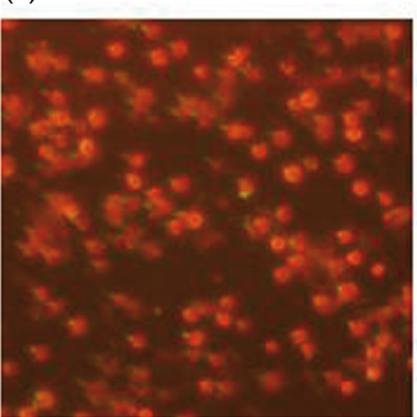

(c)

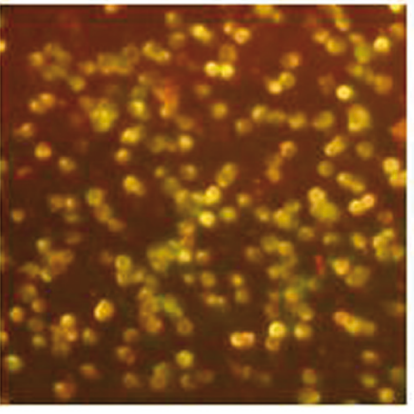

(e)

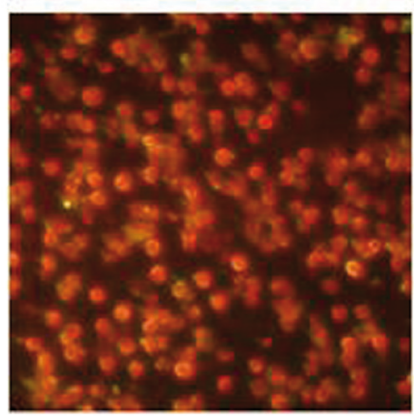

Fig. 3

Expression of DENV-2 E protein of chimeric viruses in C6/36 cells The legend: IFA. JED2V (a), JED2-1770V (b), DENV-2 (c) and JEV (d), and mock (e).

(a)

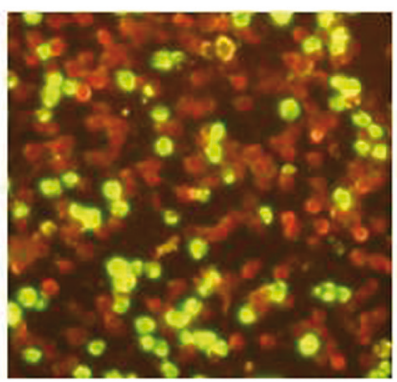

(d)

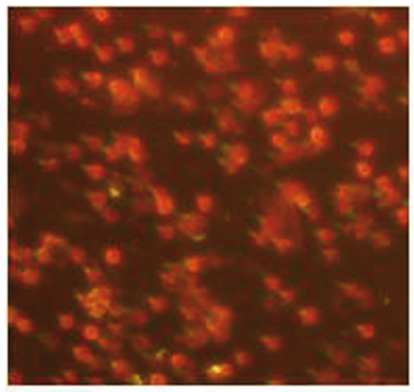

(b)

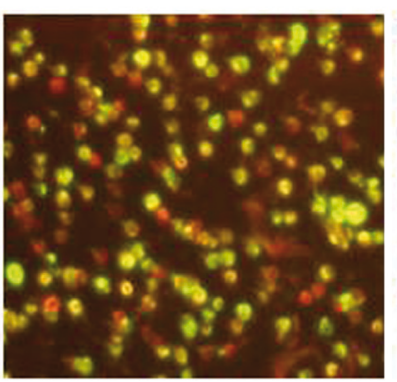

(e) (c)
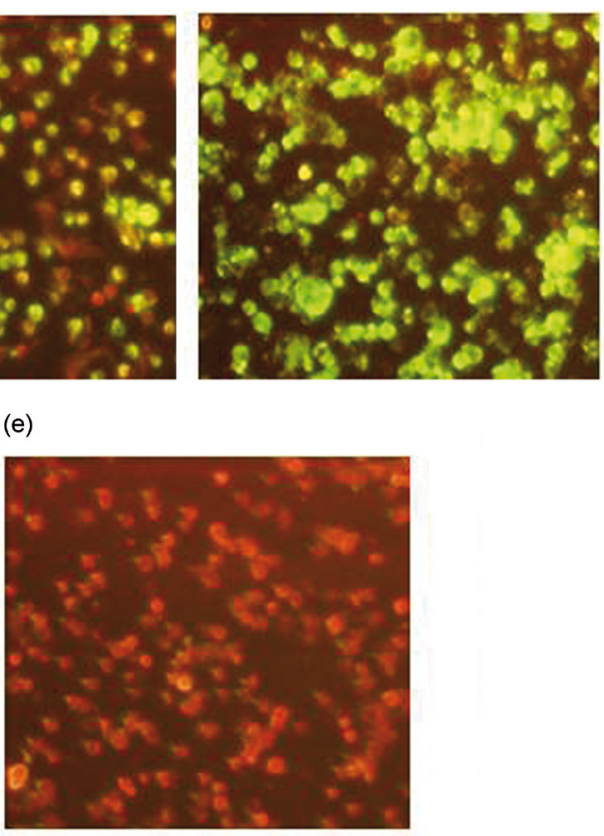

Fig. 4

Expression of JEV NS1 protein of chimeric viruses in C6/36 cells The legend: IFA. JED2V (a), JED2-1770V (b), DENV-2 (c), and JEV (d), and mock (e). 


\section{Immunogenicity of chimeric viruses}

To evaluate the immunogenicity of the chimeric virus, we have immunized Balb/C mice with the chimeric virus. Four weeks after immunization, the anti E protein IgG levels of immune sera were detected by recombinant DENV-2 E III protein coated on 96-well plates. The results proved that the $\mathrm{A}_{450}$ values of mouse sera from the chimeric virus and DENV-2 immunized groups were significantly higher than those from the JEV immunized and negative control groups at every dilution $(\mathrm{P}<0.05)$ (Fig. 6). These results indicate that the mice immunized with the chimeric virus were able to produce a specific anti-DENV-2 E protein IgG antibody.

To evaluate the neutralizing activity of mouse sera of the chimeric virus immunized group, we used the serum dilution neutralization assay to determine the neutralization titer of the serum. The serum antibody titers of these two chimeric virus strains were up to $1: 10$. The serum antibody titers of the positive control DENV-2 were up to $1: 20$ as shown in Table 1.

\section{Discussions}

In our previous study, we established the infectious clone of JEV SA14-14-2 strain and on this basis we have constructed JEV replicon vectors $\mathrm{pFull} \Delta \mathrm{prM} / \mathrm{E}$ and $\mathrm{pPartial} \Delta \mathrm{prM} / \mathrm{E}$ with full or partial structural protein gene prM/E (Wei et al., 2009). Based on previous study, we established two chimeric virus clones pJED2 and pJED2-1770 through inserting full length $\mathrm{prM} / \mathrm{E}$ gene to $\mathrm{pFull} \Delta \mathrm{prM} / \mathrm{E}$ or $\mathrm{C}$ terminal $213 \mathrm{bp}$ deleted DENV-2 prM/E gene to pPartial $\Delta \mathrm{prM} / \mathrm{E}$. After transfecting BHK-21 cells with in vitro transcripts of these two chimeric viruses, two Japanese encephalitis/Dengue type 2 chimeric virus strains (JED2V and JED2-1770V) were rescued. The rescued chimeric virus strains have been verified to express the envelope protein of DENV-2 by RT-PCR, IFA, Western blot and exerted cytopathic effects such as cell swelling and aggregation similarly to parent strains. However, the chimeric virus could not be detected in BHK-21 cells after any of five passages. It indicated that the chimeric virus RNA cannot infect BHK-21 cells although with successful virus assembly and exocytosis. Both, BHK-21 and C6/36, cell lines are sensitive to JEV and DENV-2. Each protein of the parent virus strain is conserved after long term evolution in nature. These proteins are able to synergize with viral and cellular parts in viral replication and interact with host cells. The incompatibility of the chimeric virus may be caused by genetic heterogeneity. The change of the natural synergy responds to the change of biological characteristics such as host tropism and some unexpected changes. There were other studies of chimeric viruses with similar results. ChimeriVax-JE chimera constructed by Guirakhoo et al. (a)

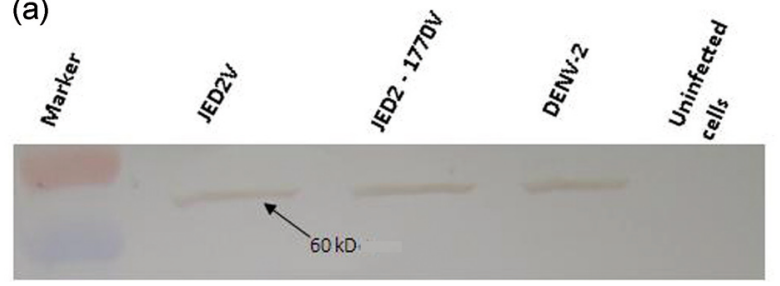

(b)

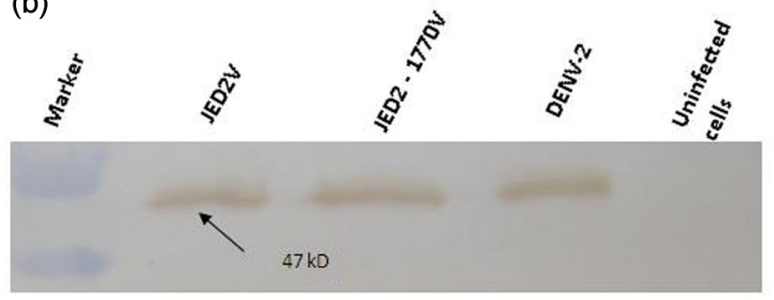

Fig. 5

DENV-2 E and JEV NS1 proteins of chimeric viruses in C6/36 cells The legend: Western blot analysis. DENV-2 E protein (a) and JEV NS1 protein (b).

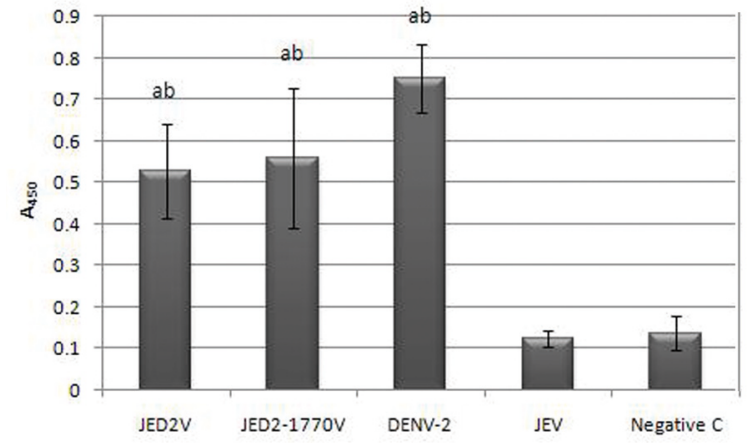

Fig. 6

IgG antibodies to DENV-2 E protein induced in mice by chimeric viruses

The legend: ELISA, sera diluted 1:100. The values differed significantly from those of negative control (NC) (a) and JEV (b), respectively.

Table 1 Neutralization titration of sera of mice immunized with chimeric viruses, DENV-2 and JEV

\begin{tabular}{lcccc}
\hline \multirow{2}{*}{ Immunization with } & \multicolumn{4}{c}{ No. of positive sera/total of sera } \\
\cline { 2 - 5 } & \multicolumn{4}{c}{ Serum dilution } \\
\cline { 2 - 5 } & $1: 5$ & $1: 10$ & $1: 20$ & $1: 40$ \\
\hline JED2V & $5 / 5$ & $3 / 5$ & $0 / 5$ & $0 / 5$ \\
JED2-1770V & $5 / 5$ & $4 / 5$ & $0 / 5$ & $0 / 5$ \\
DENV-2 & $5 / 5$ & $5 / 5$ & $3 / 5$ & $0 / 5$ \\
JEV & $0 / 5$ & $0 / 5$ & $0 / 5$ & $0 / 5$ \\
Negative control & $0 / 5$ & $0 / 5$ & $0 / 5$ & $0 / 5$ \\
\hline
\end{tabular}


(1999) has a similar performance in Vero, LLC-MK and C6/36 cells but has different performance with parent virus strains in MRC-5 and FRh1 cells where CPE was not observed even when infecting with high viral titers (up to $10^{6}$ $\mathrm{PFU} / \mathrm{ml}$ ). The replication ability of chimeric virus of TBEV and DV4 decreased in monkey cells but was impaired in mosquito cells (Pletnev et al., 1992).

Furthermore, we immunized Balb/C mice to determine the immunogenicity of the chimeric virus. Four weeks after immunization, using recombinant DENV-2 E III protein as antigen and serial dilution of mouse serum, the ELISA results showed that $A_{450}$ value of each dilution of mouse sera from the chimeric virus and DENV-2 immunized groups was higher than those of JEV immunized group and negative group $(\mathrm{P}<0.05)$. This indicates that the Balb/C mice immunized with chimeric virus can produce specific antiDENV-2 protein IgG antibody. Neutralization assay showed that the serum antibody titers of these two chimeric virus strains were around 1:10, while the serum antibody titers of the positive control-DENV-2 were up to 1:20. However, prM and $\mathrm{E}$ genes from DENV inserted into some other flavivirus replicon vectors (YF-17D, DEN2 PDK-53, rDEN4 30 ) reached 1:40 neutralizing titers or higher (Guirakhoo et al., 2000, 2001; Huang et al., 2003; Durbin, 2006). This is the first time to express the prM/E protein with the SA14-14-2 vector, so much more study is needed to explore the compatibility of SA14-14-2 backbone with other foreign proteins. We hypothesized that lower $\mathrm{A}_{450}$ value of ELISA and the lower neutralizing titers of mouse sera from the chimeric virus immunized mice group than from DENV-2 immunized group may relate to the weaker replication ability caused by the genetic heterogeneity.

Acknowledgments. This work was supported by China MegaProject for Infectious Diseases grants (No. 2012ZX10004215 and 2012ZX10004219) from the Ministry of Science and Technology and the Ministry of Health.

\section{References}

Bittle JL, Houghten RA, Alexander H, Shinnick TM, Sutcliffe JG, Lerner RA, Rowlands DJ, Brown F (1982): Protection against foot-and-mouth disease by immunization with a chemically synthesized peptide predicted from the viral nucleotide sequence. Nature 298, 30-33. http://dx.doi. org/10.1038/298030a0

Boonyakiat Y, Hughes PJ, Ghazi F, Stanway G (2001): Arginineglycine-aspartic acid motif is critical for human parechovirus 1 entry. J. Virol. 75, 10000-10004. http://dx.doi. org/10.1128/JVI.75.20.10000-10004.2001

Cereghino JL, Cregg JM (2000): Heterologous protein expression in the methylotrophic yeast Pichia pastoris. FEMS Microbiol. Rev. 24, 45-66. http://dx.doi.org/10.1111/j.15746976.2000.tb00532.x
Collen T, Dimarchi R, Doel TR (1991): A T cell epitope in VP1 of foot-and-mouth disease virus is immunodominant for vaccinated cattle. J. Immunol. 146, 749-755.

Cregg JM, Cereghino JL, Shi J, Higgins DR (2000): Recombinant protein expression in Pichia pastoris. Mol. Biotechnol. 16, 23-52. http://dx.doi.org/10.1385/MB:16:1:23

Ding C, Zhang D (2007): Molecular analysis of duck hepatitis virus type 1. Virology 361, 9-17. http://dx.doi.org/10.1016/j. virol.2007.01.007

Fry EE, Newman JW, Curry S, Najjam S, Jackson T, Blakemore W, Lea SM, Miller L, Burman A, King AM, Stuart DI (2005): Structure of Foot-and-mouth disease virus serotype A10 61 alone and complexed with oligosaccharide receptor: receptor conservation in the face of antigenic variation. J. Gen. Virol. 86, 1909-1920. http://dx.doi.org/10.1099/ vir.0.80730-0

Haider SA, Calnek BW (1979): In vitro isolation, propagation, and characterization of duck hepatitis virus type III. Avian Dis. 23, 715-729. http://dx.doi.org/10.2307/1589748

Hu S, Li L, Qiao J, Guo Y, Cheng L, Liu J (2006): Codon optimization, expression, and characterization of an internalizing anti-ErbB2 single-chain antibody in Pichia pastoris. Protein Expr. Purif. 47, 249-257. http://dx.doi.org/10.1016/j. pep.2005.11.014

Ito M, Yamashita T, Tsuzuki H, Takeda N, Sakae K (2004): Isolation and identification of a novel human parechovirus. J. Gen. Virol. 85, 391-398. http://dx.doi.org/10.1099/ vir.0.19456-0

Joki-Korpela P, Roivainen M, Lankinen H, Poyry T, Hyypia $\mathrm{T}$ (2000): Antigenic properties of human parechovirus 1. J. Gen. Virol. 81, 1709-1718.

Kim MC, Kwon YK, Joh SJ, Kim SJ, Tolf C, Kim JH, Sung HW, Lindberg AM, Kwon JH (2007): Recent Korean isolates of duck hepatitis virus reveal the presence of a new genoand serotype when compared to duck hepatitis virus type 1 type strains. Arch. Virol. 152, 2059-2072. http://dx.doi. org/10.1007/s00705-007-1023-0

Kim MC, Kwon YK, Joh SJ, Lindberg AM, Kwon JH, Kim JH, Kim SJ (2006): Molecular analysis of duck hepatitis virus type 1 reveals a novel lineage close to the genus Parechovirus in the family Picornaviridae. J. Gen. Virol. 87, 3307-3316. http://dx.doi.org/10.1099/vir.0.81804-0

Levine PP, Fabricant J (1950): A hitherto-undescribed virus disease of ducks in North America. Cornell. Vet. 40, 71-86.

Levine PP, Hofstad MS (1945): Duck disease investigation. Annual Report of the New York State Veterinary College, Ithaca, pp.55-56.

Ning D, Junjian X, Qing Z, Sheng X, Wenyin C, Guirong R, Xunzhang W (2005): Production of recombinant humanized anti-HBsAg Fab fragment from Pichia pastoris by fermentation. J. Biochem. Mol. Biol. 38, 294-299. http:// dx.doi.org/10.5483/BMBRep.2005.38.3.294

Niu M, Li X, Wei J, Cao R, Zhou B, Chen P (2008): The molecular design of a recombinant antimicrobial peptide $\mathrm{CP}$ and its in vitro activity. Protein Expr. Purif. 57, 95-100. http:// dx.doi.org/10.1016/j.pep.2007.08.006

Oberste MS, Maher K, Pallansch MA (2003): Genomic evidence that simian virus 2 and six other simian picornavi- 
ruses represent a new genus in Picornaviridae. Virology 314, 283-293. http://dx.doi.org/10.1016/S0042-6822(03) $00420-3$

Parry N, Fox G, Rowlands D, Brown F, Fry E, Acharya R, Logan D, Stuart D (1990): Structural and serological evidence for a novel mechanism of antigenic variation in foot-andmouth disease virus. Nature 347, 569-72. http://dx.doi. org/10.1038/347569a0

Rieder E, Henry T, Duque H, Baxt B (2005): Analysis of a footand-mouth disease virus type A24 isolate containing an SGD receptor recognition site in vitro and its pathogenesis in cattle. J. Virol. 79, 12989-12998. http://dx.doi. org/10.1128/JVI.79.20.12989-12998.2005

Roivainen M, Piirainen L, Hovi T (1996): Efficient RGD-independent entry process of coxsackievirus A9. Arch. Virol. 141, 1909-1919. http://dx.doi.org/10.1007/BF01718203

Rossmann MG, Arnold E, Erickson JW, Frankenberger EA, Griffith JP, Hecht HJ, Johnson JE, Kamer G, Luo M, Mosser AG , Rueckert RR, Sherry B, Vriend G (1985): Structure of a human common cold virus and functional relationship to other picornaviruses. Nature $317,145-153$. http:// dx.doi.org/10.1038/317145a 0

Sandhu TS, Calnek BW, Zeman L (1992): Pathologic and serologic characterization of a variant of duck hepatitis type I virus. Avian Dis. 36, 932-936. http://dx.doi. org/10.2307/1591552

Su C, Duan X, Wang X, Wang C, Cao R, Zhou B, Chen P (2007): Heterologous expression of FMDV immunodominant epitopes and HSP70 in P. pastoris and the subsequent immune response in mice. Vet. Microbiol. 124, 256-263. http://dx.doi.org/10.1016/j.vetmic.2007.04.030

Takeuchi H, Baba M, Shigeta S (1991): An application of tetrazolium (MTT) colorimetric assay for the screening of anti-herpes simplex virus compounds. J. Virol. Methods 33, 61-71. http://dx.doi.org/10.1016/0166-0934(91)90008-N

Toth TE (1970): Immunologic and serologic response of White Pekin ducklings inoculated with single and combined duck virus hepatitis and duck virus enteritis modifiedlive-virus vaccines. Avian Dis. 14, 697-705. http://dx.doi. org/10.2307/1588641
Tseng CH, Knowles NJ, Tsai HJ (2007): Molecular analysis of duck hepatitis virus type 1 indicates that it should be assigned to a new genus. Virus Res. 123, 190-203. http://dx.doi. org/10.1016/j.virusres.2006.09.007

Tseng CH,Tsai HJ (2007): Molecular characterization of a new serotype of duck hepatitis virus. Virus Res. 126, 19-31. http://dx.doi.org/10.1016/j.virusres.2007.01.012

Tseng CH, Tsai HJ (2007): Sequence analysis of a duck picornavirus isolate indicates that it together with porcine enterovirus type 8 and simian picornavirus type 2 should be assigned to a new picornavirus genus. Virus Res. 129, 104-114. http://dx.doi.org/10.1016/j.virusres.2007.06.023

van Houten NE, Zwick MB, Menendez A, Scott JK (2006): Filamentous phage as an immunogenic carrier to elicit focused antibody responses against a synthetic peptide. Vaccine 24, 4188-4200. http://dx.doi.org/10.1016/j. vaccine.2006.01.001

van Lierop MJ, van Maanen K, Meloen RH, Rutten VP, de Jong MA, Hensen EJ (1992): Proliferative lymphocyte responses to foot-and-mouth disease virus and three FMDV peptides after vaccination or immunization with these peptides in cattle. Immunology 75, 406-413.

Wang C, Wen WY, Su CX, Ge FF, Dang ZG, Duan XG, Cao RB, Zhou B, Chen PY (2008): Bursin as an adjuvant is a potent enhancer of immune response in mice immunized with the JEV subunit vaccine. Vet. Immunol. Immunopathol. 122, 265-274. http://dx.doi.org/10.1016/j. vetimm.2007.11.010

Wang L, Pan M, Fu Y, Zhang D (2008): Classification of duck hepatitis virus into three genotypes based on molecular evolutionary analysis. Virus Genes 37, 52-59. http:// dx.doi.org/10.1007/s11262-008-0233-1

Woolcock PR (2003): Duck hepatitis. In Saif YM, Barnes HJ, Glisson JR, Fadly AM, McDougald LR, Swayne DE (11th Eds): Disease of poultry, Iowa State University Press, Iowa, pp. 342-354.

Yi JZ, Liu MQ, Zhu CZ, Zhang Q, Sheng ZT, Du QY, Yan WY, Zheng ZX (2004): Recombinant bivalent vaccine against foot-and-mouth disease virus serotype O/A infection in guinea pig. Acta Biochim. Biophys. Sin. 36, 589-596. http://dx.doi.org/10.1093/abbs/36.9.589 